\title{
The Investigations of Thermomechanical Properties of Polypropylene Composites
}

\author{
Sylwester Norwiński, ${ }^{1}$ Przemysław Postawa, ${ }^{1}$ Robert Sachajko, ${ }^{2}$ \\ Pawel Palutkiewicz $₫{ }^{1}{ }^{1}$ and Tomasz Stachowiak ${ }^{1}$ \\ ${ }^{1}$ Czestochowa University of Technology, Department of Polymer Processing, Al. Armii Krajowej 19c, 42-201 Czestochowa, Poland \\ ${ }^{2}$ Polimarky Sp. z o. o. Sp. K. ul. Bieszczadzka 10 a, 35-082 Rzeszów, Poland \\ Correspondence should be addressed to Paweł Palutkiewicz; palutkiewicz@ipp.pcz.pl
}

Received 25 October 2018; Revised 4 February 2019; Accepted 24 March 2019; Published 17 April 2019

Academic Editor: Leonard D. Tijing

Copyright (C) 2019 Sylwester Norwiński et al. This is an open access article distributed under the Creative Commons Attribution License, which permits unrestricted use, distribution, and reproduction in any medium, provided the original work is properly cited.

\begin{abstract}
The article presents the results of the investigations of isotactic polypropylene composites with the following fillers: flame retardants, glass fiber, glass beads, and talc. The process of preparing composites and test samples is described. The investigations were performed using the DMTA method. The evaluation of thermal effects for the investigated molded parts using special device was also presented. The scope of the research included ten polypropylene composites with different content and type of fillers. These measurements allowed us to determine the influence of the filler type and content on the dynamic mechanical properties of iPP composites. The results will be useful for determining the scope of application of the mentioned materials in various fields of industry in the future.
\end{abstract}

\section{Introduction}

The global increase in prices of raw materials and traditional materials used in various industries such as construction, automotive industry, and medical industry forces us to look for cheaper alternatives [1]. Therefore, polymer materials, which are characterized by relatively low production cost and good processing and functional properties, dominated many branches of industry in the last century. Taking into account automotive industry as an example, the average share of polymers in the mass of vehicles produced in $1977 \div 1995$ was approx. $8 \%(80 \div 120 \mathrm{~kg})$. Currently, the total mass of polymers used in vehicles, averaged on the basis of several car brands (including BMW 3, Audi A4, Skoda Octavia, and Opel Astra) is approx. $433.5 \mathrm{~kg}$ [2]. In comparison to 1975, it is almost a six-fold increase at a rate of approx. 30\% of weight of the whole vehicle. By 2030 it is expected to increase to approx. $70 \%[3,4]$.

In many cases, mechanical and flammable properties of polymeric materials (homopolymers) limit the scope of their application in certain conditions. Therefore, homopolymers are more and more often being replaced with polymeric composites. In order to modify their physical properties, many additional materials can be added to base polymers. As a result, polymeric composites are formed [2-6]. The purpose of such a modification may change chemical resistance, processing properties, dimensional stability, damping properties, etc. [7, 8]. Modification of materials in terms of their flammability is also an extremely important issue. Polymer composites modified with flame retardants are frequently used when excellent fire resistance is required $[9,10]$.

There are some properties of materials that determine whether it can be used in different types of constructions: mechanical strength, stiffness, ability to absorb energy, insulation ability, tribological properties, thermal expansion ability, and also resistance to high temperatures [11, 12].

Glass fiber, which has been used as a filler for polymeric materials since 1970, has a direct effect on thermomechanical properties of polymer composite, wherein composites which are filled with this filler has favorable properties. [13-15]. Also, addition of talc to the polymer increases some mechanical properties and decreases anisotropy of shrinkage $[16,17]$. 


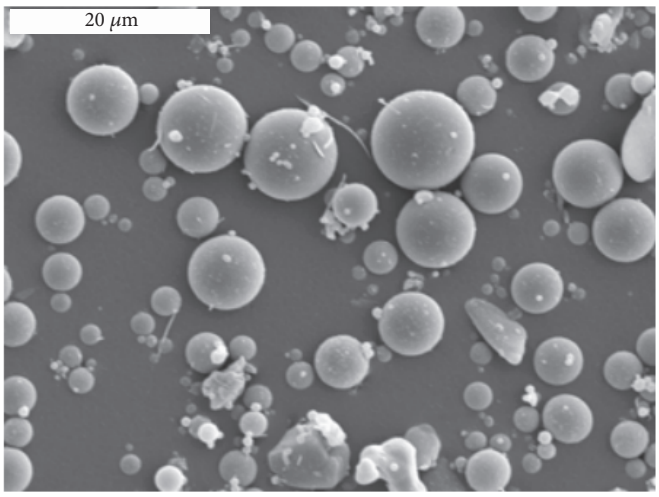

(a)

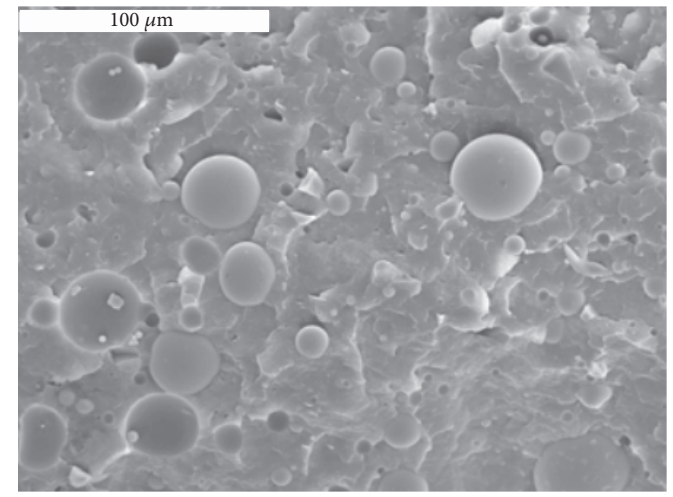

(b)

FIGURE 1: Microscopic photo of glass beads (a) and PP composite with 10\% content of glass beads (b) [4].

The purpose of the research was to determine changes in thermomechanical properties of polymer composites on the base of polypropylene using a variety type of fillers. The use of iPP homo- or copolymer is depended on application and range of temperature of use. Car bumpers for an example are made of iPP copolymer or blends modified by thermoplastic elastomers because the lower stiffness in the low temperature is needed $[5,6]$.

\section{Materials}

The scope of the research included the DMTA analysis (Dynamic Mechanical Thermal Analysis) of 10 polymer composites based on polypropylene (PP) with a different content of fillers. The following materials were used as fillers: glass fiber, glass beads, white talc, and flame retardant. Composites were made based on polypropylene material (PP), with trade name Moplen HP500N (Basell Orlen Polyolefins). Such materials are widely used in the household industry, automotive industry, toys industry, and electrical engineering $[5,6]$. The samples were prepared by injection molding. The polymer composites were divided into 4 groups of fillers.

The first filler that was used for composites processing was glass fiber. These materials, which are used in the industries of household, automotive industry and electrical engineering, are also an alternative to PA 6. The materials were filled with ECS 13-4.5-508A glass fiber, E type of glass, CS cut, fiber diameter $13 \mu \mathrm{m}$, and fiber length $4.5 \mathrm{~mm}$.

Another filler used in our investigations was glass beads (full GB and hollow GBL). This filler is characterized by improvement of processing properties and flow in the injected polymer: smooth surface, lowest possible ratio of surface to volume, high load bearing capacity, excellent mold flow, and uniform dispersion ability (Figure 1).

Addition of glass beads to processed polymer improves the flow in mold cavities and results in increase of mechanical properties of molded parts (surface hardness, strength, durability, and modulus of elasticity) and also has excellent chemical resistance and low deformation level $[5,6]$. The main advantages of using the spherical fillers are as follows: (i) Improved flow: the beads reduce viscosity and act as internal miniature beads bearings that improve the flow [12]. When used in combination with glass fiber, which has a different shape of particles, the beads improve fluidity and distribution of polymer in the mold and, as a result, increase the tool life and positively affect the production rate.

(ii) Decreased deformation and shrinkage of molded parts: because of the beads, the molded parts get a better dimensional stability of the finished product as a result of reduced shrinkage and reduced anisotropy in the range of longitudinal and transverse shrinkage.

(iii) Mechanical properties: fillers of this type improve the properties of the finished product by increasing flexural modulus and surface hardness and also by improving the stress distribution (Figure 2).

(iv) Dimensional stability: achieved due to stress distribution of particles of a spherical shape. This kind of behavior is illustrated in Figure 2.

The A-3000 type glass beads are used as the filler. Their average particle size is about $30 \div 50 \mu \mathrm{m}$, and density is $2.5 \mathrm{~g} /$ $\mathrm{cm}^{3}$.

The third group of analyzed polymer composites was based on polypropylene with flame retardant and talc. Talc and flame retardant ADK STAB FP-2100JC (nitrogen/ phosphorus-based intumescent system showing excellent flame retardancy with retention of mechanical properties) were used to modify the mentioned above materials. ADK STAB FP-2100JC shows excellent processing stability while being combined with thermoplastics. In particular, it is recommended to use with polypropylene (homo and copolymer), polyethylene of high and low density, and also copolymers of ethylene and vinyl acetate. Thermal decomposition temperature of the flame retardant is higher than $300^{\circ} \mathrm{C}$, and the weight of the mixture includes organic and inorganic substances: diphosphoric acid (55\%), phosphoric acid (35\%), and other fillers (10\%). 


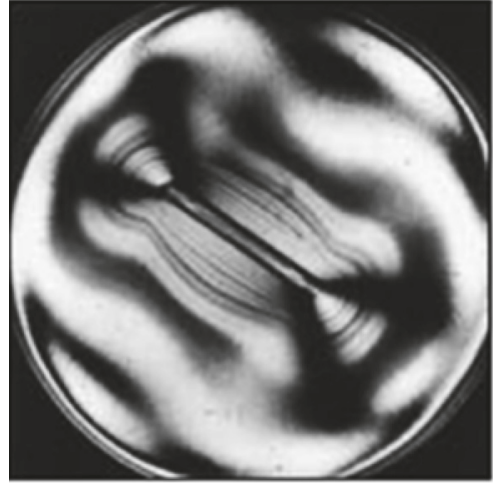

(a)

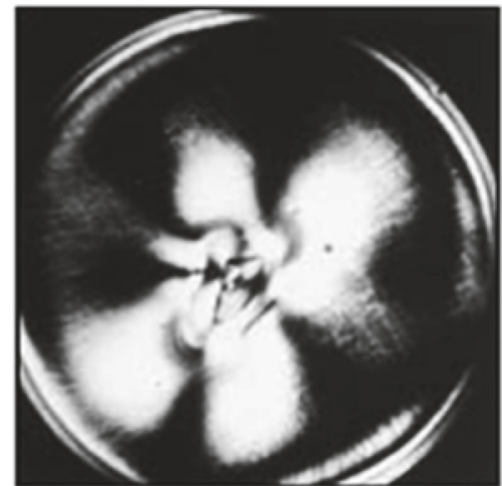

(b)

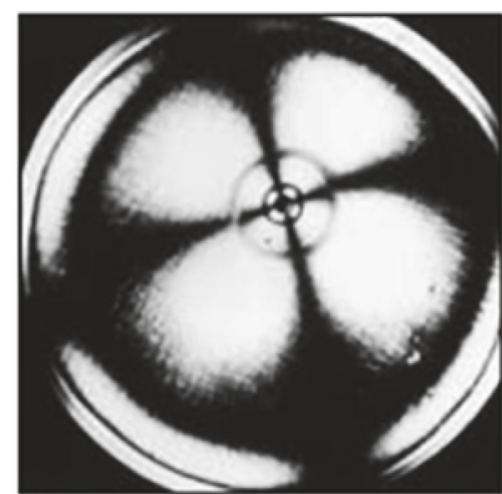

(c)

FIGURE 2: Elastooptic images of stress distribution around various types of fillers: (a) glass fiber, (b) nonuniform particles, and (c) glass beads [13].

White talc, the trade name of which was Luzenac OXO, was the last filler. It is primarily used to get an aesthetic surface and to modify the mechanical and processing properties (mainly to reduce shrinkage).

\section{Preparation of the Samples}

Polymer composites were manufactured by Polimarky company (Poland), using a corotating twin screw extruder. The following polymer and PP composites were used in this investigation:

(1) Virgin, unfilled polypropylene PPH - polypropylene homopolymer

(2) PPH with 15\% wt. talc content: "PPH9 T 15"

(3) PPH with 20\% wt. talc content: "PPH9T 20"

(4) $\mathrm{PPH}$ with $20 \%$ wt. content of dolomite talc and $6 \%$ of ADK STAB FP-2100JC content: "PPH9 T 20 V0"

(5) PPH with 30\% wt. talc content: "PPH9 T 30"

(6) PPH with 30\% wt. fiberglass content: "PPX12 GF 30"

(7) PPH with 40\% wt. fiberglass content: "PPX12 GF 40"

(8) $\mathrm{PPH}$ with $30 \%$ wt. content of glass balls (hollow): "PPH10 GB 30 L"

(9) $\mathrm{PPH}$ with $30 \%$ wt. content of glass balls (solid): "PPH10 GB 30"

(10) PPH with 30\% wt. content of ADK STAB FP-2100JC: "PPH10 WH HF V0"

Before injection molding, the granulates were being dried for 2 hours at $65^{\circ} \mathrm{C}$ in a laboratory oven Shini CD9 Cabinet. The test samples were made using Krauss Maffei KM 65 160C4 injection molding machine. The injection conditions were as follows:

(i) Injection temperature: $225^{\circ} \mathrm{C}$

(ii) Injection pressure: $80 \mathrm{MPa}$

(iii) Mold temperature: $40^{\circ} \mathrm{C}$ (iv) Hold pressure: $40 \mathrm{MPa}$

(v) Injection velocity: $42 \mathrm{~cm}^{3} / \mathrm{s}$

(vi) Injection time: $0.73 \mathrm{~s}$

(vii) Hold time: $15 \mathrm{~s}$

(viii) Cooling time: $15 \mathrm{~s}$

\section{Methodology}

4.1. The Thermal Analysis of Dynamic Mechanical Properties. The thermal analysis of dynamic mechanical properties of the samples was performed by using the DMA device Netzsch 242C equipped with a sample holder for three-point bending of the samples in the form of a beam (dimensions $50 \times 10$ $\mathrm{x} 4 \mathrm{~mm}$ ). During the analysis, the test sample was heated from $-50^{\circ} \mathrm{C}$ to $140^{\circ} \mathrm{C}$ at a heating rate of $3 \mathrm{~K} / \mathrm{min}$. The test was performed for the frequency of $10 \mathrm{~Hz}$ and strain amplitude of $120 \mu \mathrm{m}$. The values of the storage modulus E' and the loss factor $\operatorname{tg} \delta$ were determined on the basis of force and deflection values, taking into account the transverse dimensions of the sample. The test results are illustrated in the form of a dependency graph of a loss factor $\operatorname{tg} \delta$ and a storage modulus E' towards the temperature.

\subsection{Evaluation of Heat Resistance for the Investigated Molded} Parts. Evaluation of heat resistance for the investigated molded parts was performed using a special test stand, which was made by the authors of the work. This test stand was also described in author's work [17]. We followed the methods of Palutkiewicz et al. 2015. The heat resistance is dependent on the kind of tested material, its properties, and it is characterized in terms of heat transfer. For solids and liquids this ratio depends on the temperature, while for gases it also depends on pressure. In the moderate pressure range, for gases it varies between 0.005 and $0.5 \mathrm{~W} / \mathrm{mK}$, for the liquid from 0.09 to $0.7 \mathrm{~W} / \mathrm{mK}$ and for solids from 0.02 to 429 $\mathrm{W} / \mathrm{mK}$. [17].

For the heat resistance measurements, it was assumed that the heat source has a constant power and the system is in steady state; that is, the temperature does not change with 


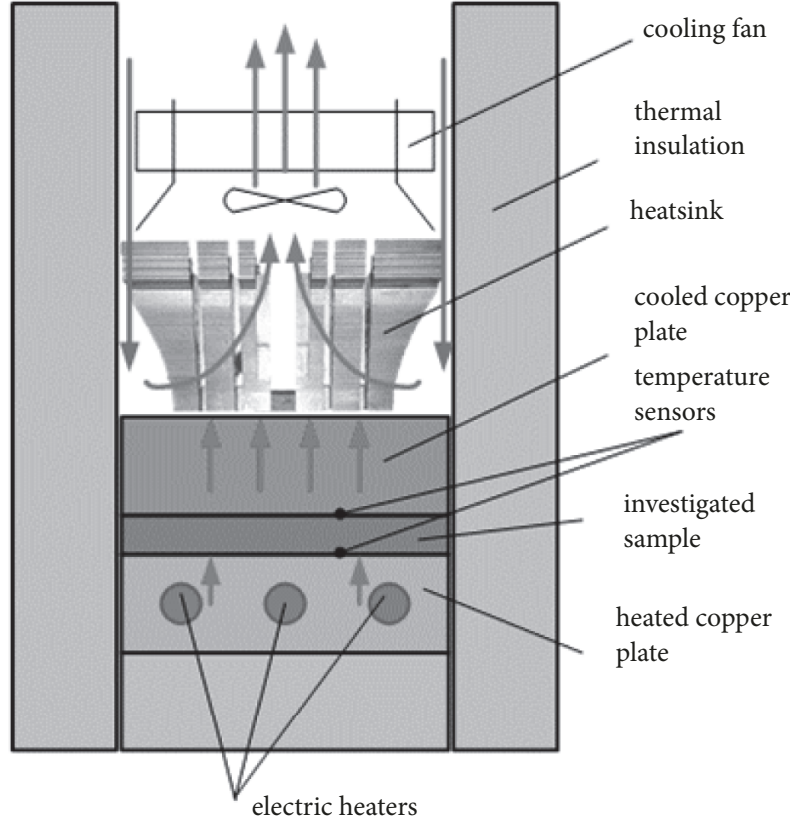

Figure 3: Diagram of the device for determining the heat resistance of test samples [17].

time. It is also assumed that the system is one-dimensional.

The construction scheme of devise is shown in Figure 3. In the lower part there is a copper plate in which the electrofusion heaters are placed. The temperature of these heaters captures thermocouple T1. The heaters located in the heating plate transmit heat through the sample to the cooled plate located above. Part of the thermal energy transferred from the heater is absorbed by the test material, and the rest is transferred to cooled plate. The temperature value is measured by the thermocouple T2. The radiator and fan located above the top plate are designed to dissipate heat.

The device is designed to force the heat flow in only one direction between the heated plate and the cooled one. The size of the sample is the same as the size of the heating plate, which minimizes the convection of air on the side of the plate.

Since the samples prepared for investigation to the tensile test had a dumbbell shape, it was necessary to have cut-out sections with a length of $80 \mathrm{~mm}$, and positioning in the shape of a flat plate with eight pieces of samples (Figure 4) [17].

The testing stand used in investigations was shown in Figure 5. It consists of a measuring chamber (picture visible without the front cover with thermal insulation), the temperature controller module and recording module of the temperature of the hot and cold plates T1 and T2. The controller is connected to the computer which is recording temperature readings of thermocouples $\mathrm{T} 1$ and $\mathrm{T} 2$ during the measurement [17].

The start measurement conditions were as follows:

(i) temperature of the test (hot plate): $85^{\circ} \mathrm{C}$,

(ii) the temperature of the cold plate: $25^{\circ} \mathrm{C}$,

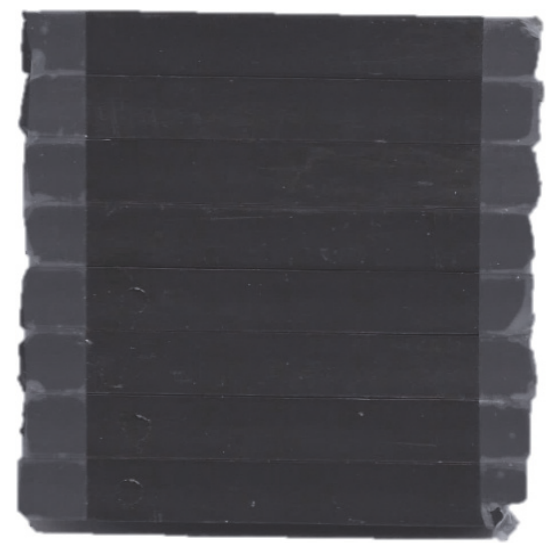

FIGURE 4: The prepared test samples: PP with talc.

(iii) stabilization time before the measurement: $15 \mathrm{~min}$,

(iv) measurement time: to stabilize the temperature.

Before measurements, between the hot and cold plates is placed insulation to stop the flow of heat. Only after stabilization of the temperature of the hot plate, recording starts. Next, insulation is removed by replacing the test sample and presses the upper plate spring force and closes the cover with thermal insulation. It begins with the heat absorption by the sample and the heat transfer to the cold plate. The measurement is carried out to the thermal stabilization of the entire system.

\section{Results of DMTA Investigations}

Figures 6-9 present the changes of values of storage modulus $E^{\prime}$ and loss factor $\operatorname{tg} \delta$, depending on the temperature of polypropylene and polypropylene composites with the mentioned above flame retardants and fillers.

Figure 6 presents the changes of values of storage modulus $E^{\prime}$ and loss factor $\operatorname{tg} \delta$ in a function of temperature for the composites with variable filler content in the form of glass fiber. The filler caused a significant increase in the storage modulus value (from $4800 \mathrm{MPa}$ for a basic PP to $10200 \mathrm{MPa}$ for a composite with a filler content of $30 \%$ and $12800 \mathrm{MPa}$ for a sample containing $40 \%$ of glass fiber). Characteristics of the changes in storage modulus value were similar for all the materials, and the relative differences between them were almost the same in the whole temperature range. Adding glass fiber to PP homopolymer has significantly increased its temperature resistance, which is shown by the storage modulus values registered at above $100^{\circ} \mathrm{C}$. Values of the tested composites varied between $4500 \mathrm{MPa}$ and $6000 \mathrm{MPa}$ in comparison to the base PP, the value of which was below $500 \mathrm{MPa}$. While analyzing the changes of the loss factor $\operatorname{tg} \delta$, it was clear that the test samples with varying glass fiber content showed transformation of the glass transition at a similar temperature rate of approx. $10-15^{\circ} \mathrm{C}$. It has been shown in Figure 6(b), the maximum value of $\operatorname{tg} \delta$ at the glass transition temperature is between 0.085 and 0.11 . In the case of materials filled with glass fiber, the loss factor $\operatorname{tg} \delta$ had a similar value, 


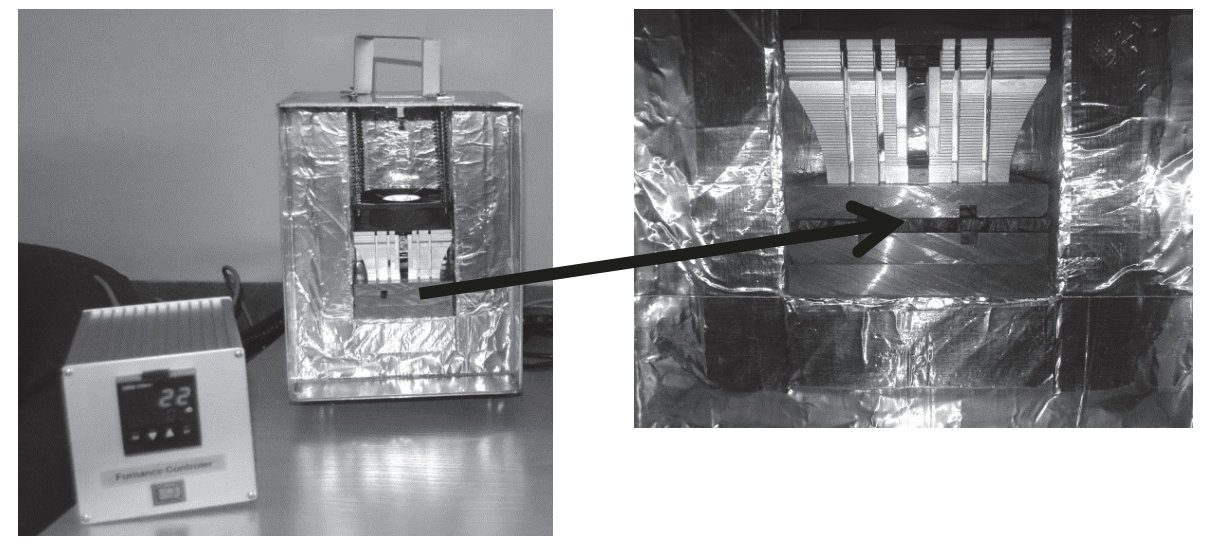

(a)

(b)

FIGURE 5: The view of the measuring equipment (a) and the mounting location of the sample (b) [17].
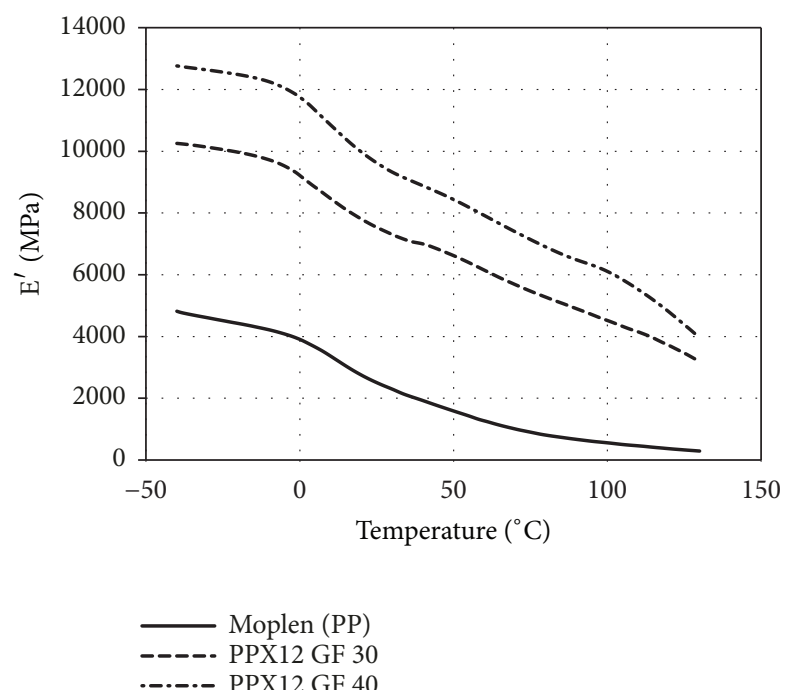

(a)

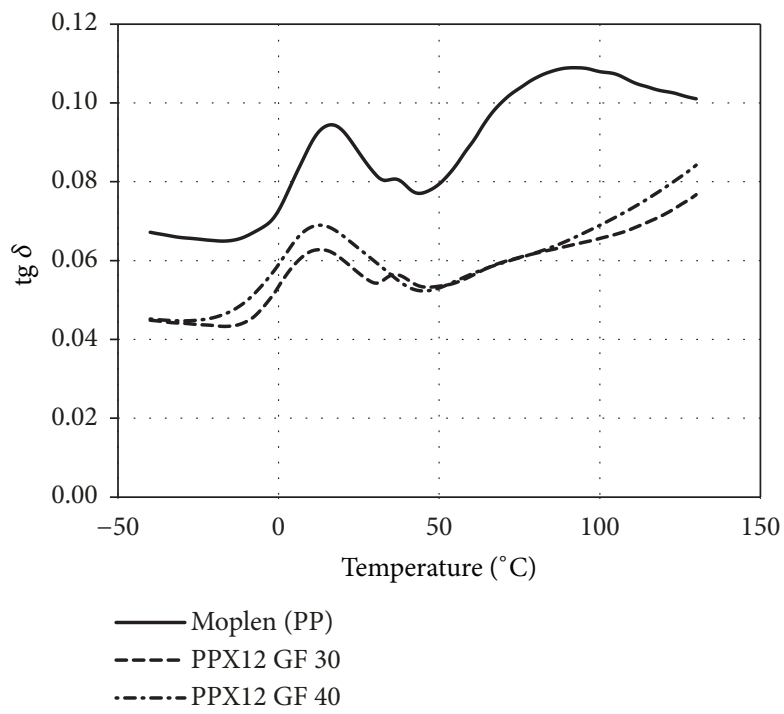

(b)

Figure 6: Changes of the storage modulus E' (a) and the loss factor tg $\delta$ value (b) as a function of temperature of Moplen polypropylene (PP), with a filler in the form of glass fiber 30\% (GF30), 40\% (GF40). 


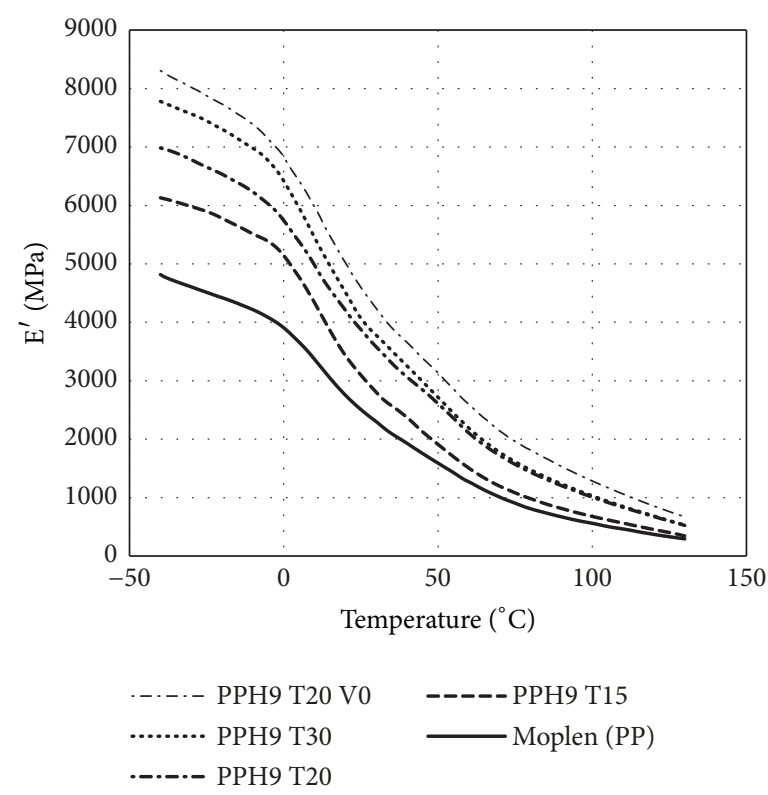

(a)

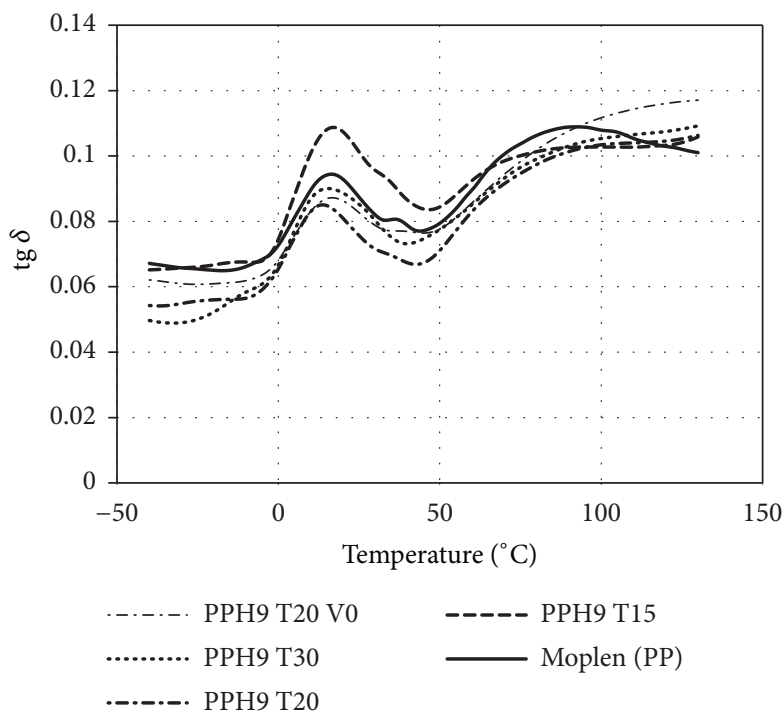

(b)

FIGURE 7: Changes of the storage modulus E' (a) and the loss factor tg $\delta$ value (b) as a function of temperature of Moplen polypropylene (PP), with filler in the form of talc 15\% (T15), 20\% (T20), 30\% (T30), and talcum $20 \%$ with flame retardant (T20 V0).

but at the same time it was significantly lower than that in the case of the base PP.

Figure 7 shows the changes of values of the storage modulus $\mathrm{E}^{\prime}$ and the loss factor $\operatorname{tg} \delta$ in a function of temperature for the composites with variable content of talc and flame retardant. Similarly to the case of glass fiber, the addition of talc caused an increase of the value of storage modulus E. Very regular and gradual change of the E' value can be seen, along with increasing share of talc in the composite. However, this change was not as significant as it was with glass fiber. The addition of $30 \%$ of talc increased the E' value from $4800 \mathrm{MPa}$ to $7800 \mathrm{Mpa}$; however, in the case of a composite containing $20 \%$ of talc and flame retardant, this value increased to more than $8300 \mathrm{MPa}$. It should also be noted that if the temperature is above $120^{\circ} \mathrm{C}$, the difference in the $\mathrm{E}^{\prime}$ values is minor, and in the case of "PPH9 T15" it may be compared to the unfilled material. Comparing to the addition of glass fiber, the addition of talc did not cause any significant changes of the value of loss factor $\operatorname{tg} \delta$ in the function of temperature for the composites filled with talc. The tested composites with variable amount of talc showed transformation of the glass transition at approx. $15^{\circ} \mathrm{C}$. Intensity of transition was very similar for all the samples apart from the sample containing $15 \%$ of talc. The results showed that the damping properties were not affected by the addition of talc.

Figure 8 shows the results of dynamic testing by using DMTA method for the composite containing 20\% of talc and $6 \%$ of flame retardant ADK STAB FP-2100JC "PPH9 


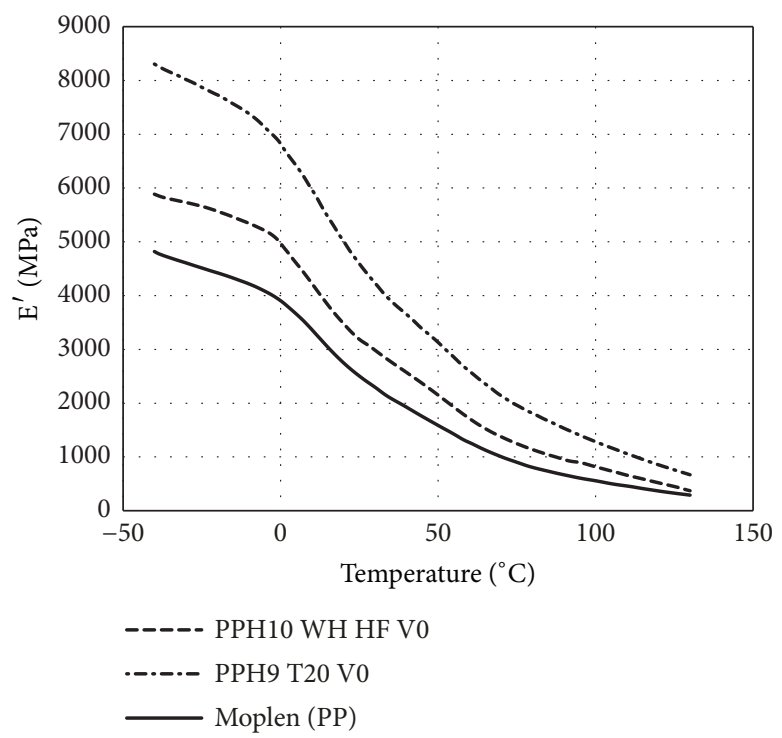

(a)

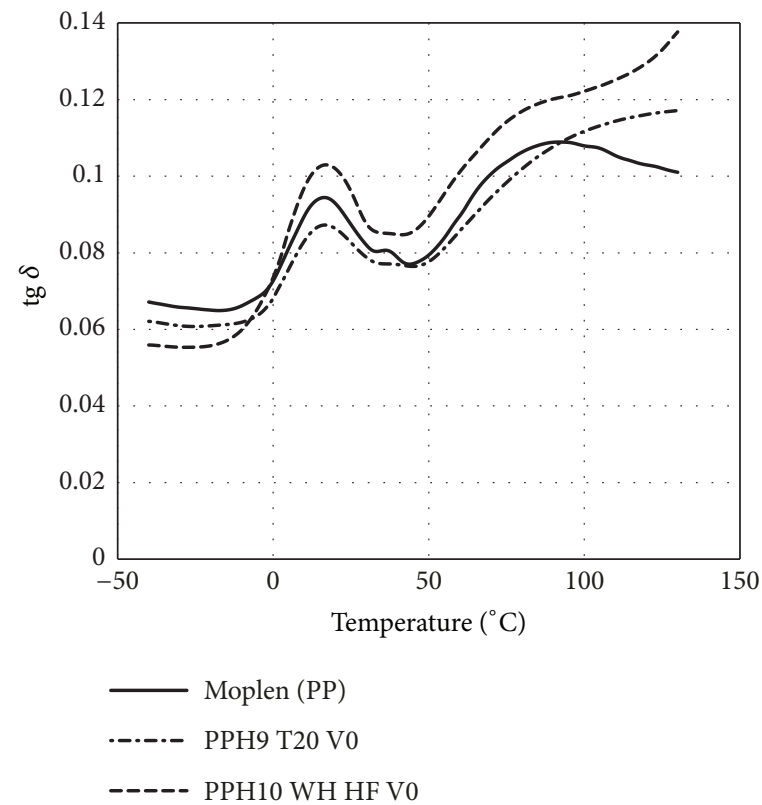

(b)

Figure 8: Changes of the storage modulus E' (a) and the loss factor tg $\delta$ value (b) in temperature of Moplen polypropylene (PP), with flame retardant ADK STAB FP-2100JC 30\% (PPH10 WH HF V0) and talc dolomite 20\% and ADK STAB FP-2100JC 6\% (T20 V0).

T20 V0", as well as the composite containing 30\% of flame retardant ADK STAB FP-2100JC “PPH10 WH HF”. The E' value of each composite was greater compared to the starting material (PP) and reached $5900 \mathrm{MPa}$ for PPH10 WH HF V0 and $8300 \mathrm{MPa}$ for T20 V0. It means that talc had a higher impact on the E' value compared to the flame retardant. As the temperature rises, the difference between the E' values for the composites and for the base material (PP) was reduced, and they reach similar values at $130^{\circ} \mathrm{C}$. The difference in temperature for PP and PPH 9 T20 V0 was $380 \mathrm{MPa}$, and for PPH10 WH HF V0 it was only $80 \mathrm{MPa}$. Changes of the loss factor value $\operatorname{tg} \delta$ showed that the glass transition temperature was approx. $15^{\circ} \mathrm{C}$. The $\operatorname{tg} \delta$ value for the composites in the range of negative temperatures was lower compared to the unmodified material. In the range of temperatures above $90^{\circ} \mathrm{C}$, they take higher values of $\operatorname{tg} \delta$.

The addition of $30 \%$ of glass beads (PPH10 $30 \mathrm{~GB}$ ) and $30 \%$ of glass microspheres (GB PPH10 30L) had the lowest impact on the storage modulus E' (Figure 9). According to the shown graphs, fillers in the form of glass beads in the polypropylene composite did not cause any significant changes in the value of E' compared to the previously discussed materials. The value of storage modulus E' of the material filled with glass beads increased by $500 \mathrm{MPa}$ at a 


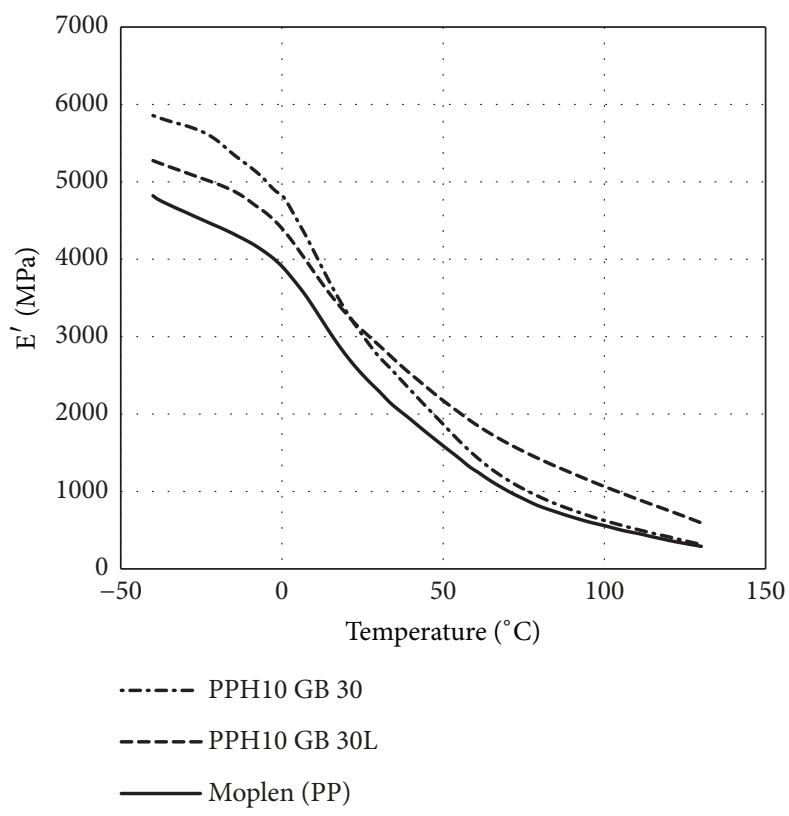

(a)

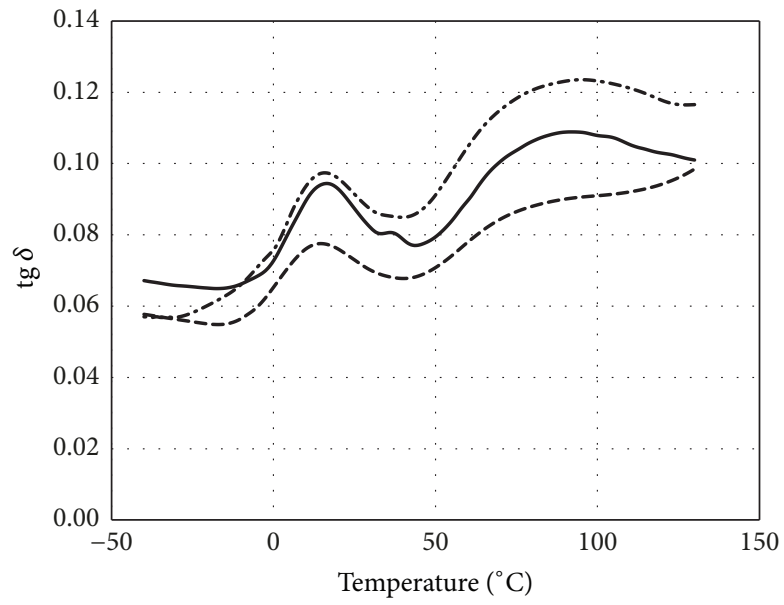

Moplen (PP)

PPH10 GB 30L

PPH10 GB 30

(b)

FIGURE 9: Changes of the storage modulus E' (a) and the loss factor tg $\delta$ value (b) as a function of temperature of Moplen polypropylene (PP), with a filler in the form of hollow glass beads $30 \%$ (GB PP 30) and solid glass beads 30\% (PP GB 30L).

temperature of $-40^{\circ} \mathrm{C}$; however, the value of the composite filled with hollow glass beads increased by $1000 \mathrm{MPa}$ and reached $5850 \mathrm{MPa}$. It should also be mentioned that the difference in the E' value between the base material (PP) and the composite with hollow glass beads was $500 \mathrm{MPa}$, and this value was the same in the entire temperature range. However, in the case of a composite with full glass beads, the value of E' at a temperature above $100^{\circ} \mathrm{C}$ was comparable to the value of $\mathrm{E}^{\prime}$ for the PP homopolymer. The introduced fillers in the form of glass beads did not cause any significant changes in the curve value of loss factor $\operatorname{tg} \delta$. The $\operatorname{tg} \delta$ value for a composite with full glass beads in a temperature range from $-40^{\circ} \mathrm{C}$ to $-15^{\circ} \mathrm{C}$ was lower compared to the base PP. But these values got equal in the glass transition temperature range, and later the $\operatorname{tg} \delta$ value of the composite with full glass beads obtained higher values. The $\operatorname{tg} \delta$ value of the material filled with hollow glass beads was lower than that of the PP in the entire temperature range. Just like in the previously discussed cases, composites with glass beads showed the change of glass transition at approx. $15^{\circ} \mathrm{C}$.

\section{Results of the Heat Resistance Measurements}

The temperature of the cold plate vs. time for each sample was presented in Figures 10-14. 


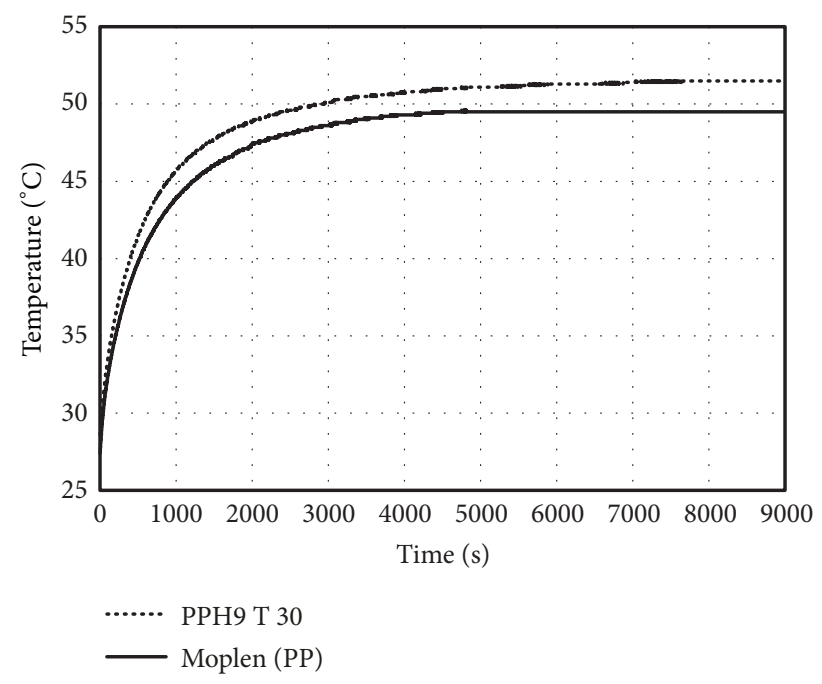

FIGURE 10: Temperature changing diagram (temp. vs. time) samples for PPH9 T 30 and unfilled PP.

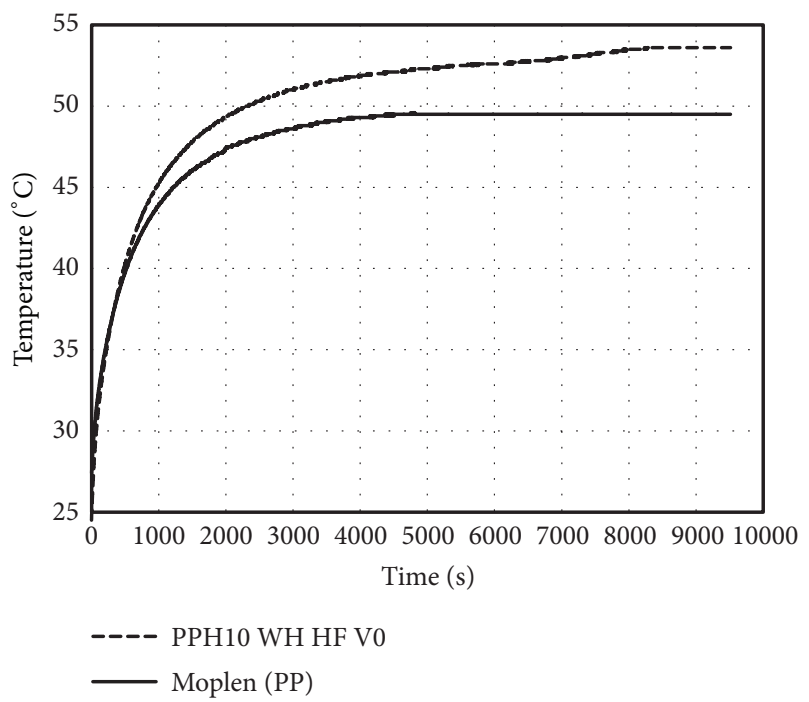

FIGURE 11: Temperature changing diagram (temp. vs. time) samples for PPH10 WH HF V0 and unfilled PP.

From Figure 10 it can be seen that samples containing 30\% of talc PPH9 T 30 and the sample with $36 \%$ content of flame retardant had a higher heat resistance as compared with the base material. For unfilled PP (Figure 11), the temperature of both the upper plate (the area with lower temperature) and the bottom temperature (the area with a higher temperature) time to stabilize the temperature was approx. 30 minutes. In the tests, differences in the thermal stabilization of individual materials tested can be observed. Composites filled with hollow glass balls have a shorter thermal stabilization time (2500 s) than a composite filled with the same amount of solid glass beads. This is most likely due to the greater thermal capacity of this material.

Samples filled with glass beads (Figures 12 and 13) also showed higher heat resistance compared to the base material; however, no significant differences in time of temperature

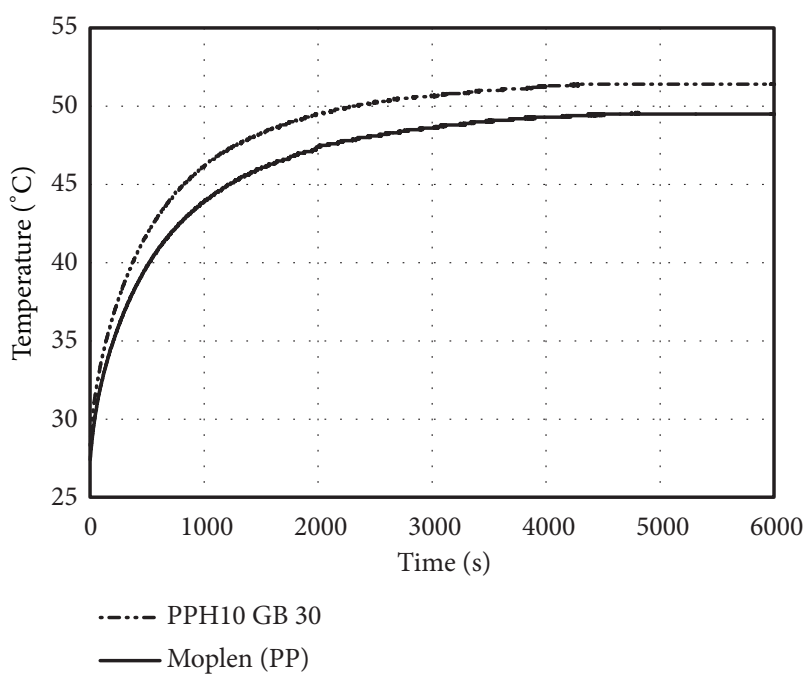

FIGURE 12: Temperature changing diagram (temp. vs. time) samples for PPH10 GB 30 and unfilled PP.

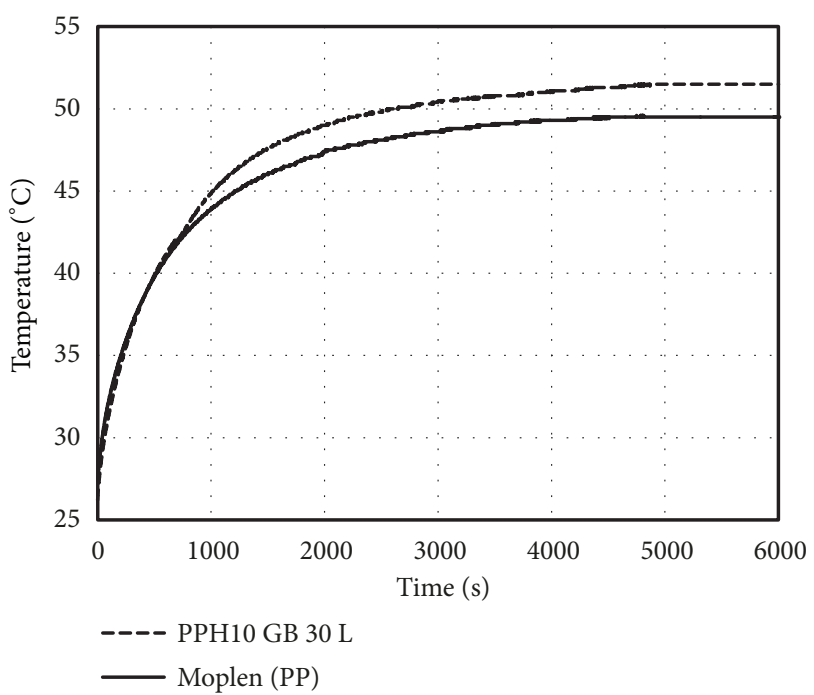

FIGURE 13: Temperature changing diagram (temp. vs. time) samples for PPH10 GB $30 \mathrm{~L}$ and unfilled PP.

stabilization in individual measurement areas were observed (only 1-1.5 $\mathrm{min}$.)

Samples filled with $40 \%$ content of glass fibers PPX 12 GF 40 (Figure 14) showed, similarly to samples with talc and flame retardant, higher heat resistance as compared to samples from unfilled PP.

The temperature of both the bottom plate (the area of lower temperature) and the upper one (the area with a higher temperature) also stabilized faster in the case of unfilled material (about 60 minutes).

\section{Conclusions}

The investigations have shown that amount and type of the filler in composites based on thermoplastic polypropylene influences on the storage modulus $\mathrm{E}^{\prime}$ and loss factor $\operatorname{tg} \delta$ 


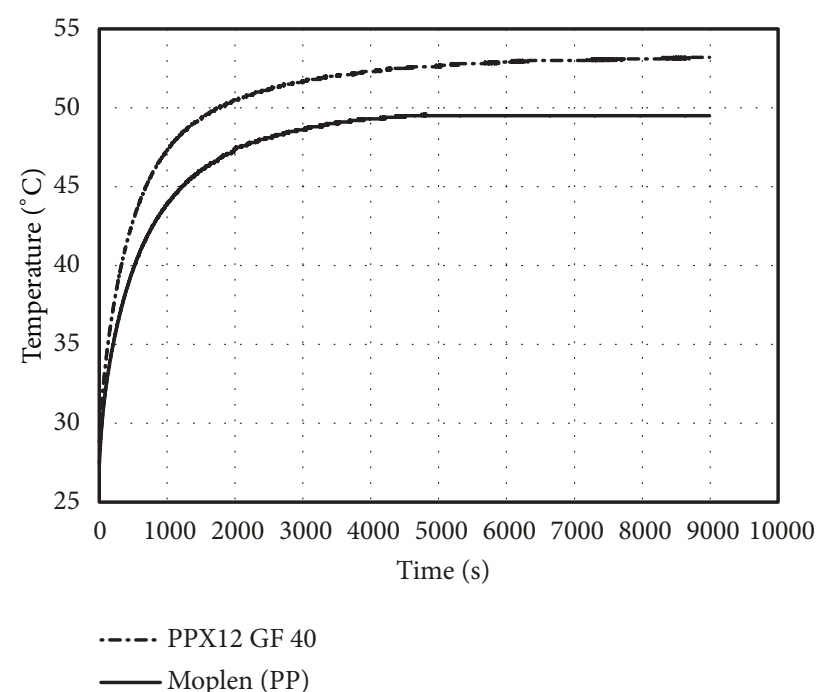

FIGURE 14: Temperature changing diagram (temp. vs. time) samples for PPX12 GF 40 and unfilled PP and unfilled PP.

values and as a result, on the properties of the obtained molded parts. Similar content of used fillers causes a wide variety of properties of the composites.

The obtained results lead us to the following conclusions:

(i) The value of storage modulus depends on the type, quantity, and physical properties of the filler.

(ii) Each of the fillers has increased the storage modulus of the prepared composite, wherein the shape and transition of the curve $\mathrm{E}^{\prime}$ and tg $\delta$ are different for the different fillers.

(iii) Glass beads have the smallest impact on the modification of the modulus of the tested PP material.

(iv) Addition of glass fiber to the PP has the strongest impact on the value of modulus and on the increase of thermal stability.

(v) The type and properties of filler have also an impact on heat transfer across the tested samples, shown as a time to stabilization.

The next planned investigations will be focused on a structural research of the prepared composite samples, to show the impact of used filler in the PPH matrix and its influence of heat transfer reported as a time to temperature stabilization of cooled plate.

\section{Data Availability}

The data for presented graphs in form of Excel (*.xlsx) files used to support the findings of this study are available from the corresponding author upon request.

\section{Conflicts of Interest}

The authors declare that they have no conflicts of interest.

\section{References}

[1] J. F. Rabek, Współczesna wiedza o polimerach (Contemporary knowledge about polymers). PWN. Warsaw, PWN. Warsaw, 2016.
[2] R. Chollakup, R. Tantatherdtam, S. Ujjin, and K. Sriroth, "Pineapple leaf fiber reinforced thermoplastic composites: Effects of fiber length and fiber content on their characteristics," Journal of Applied Polymer Science, vol. 119, no. 4, pp. 1952-1960, 2011.

[3] J. M. G. Cowie and V. Arrighi, Polymers: chemistry and physics of modern materials, CRC Press, Taylor \& Francis Group, Boca Raton, FL, USA, 2008.

[4] J. W. Kaczmar and A. Bielański, "Kompozyty na osnowie polipropylenu wzmacniane mikrokulkami szklanymi (Polypropylene based composite materials strengthened with glass beads)," Teka. Commission of Motorization and Power Industry in Agriculture, pp. 63-68, 2008.

[5] E. Charles and Jr Carraher, Carraher's Polymer Chemistry, CRC Press, 9th edition, 2016.

[6] E. Charles and Carraher Jr., Introduction to Polymer Chemistry, CRC Press, 4th edition, 2017.

[7] D. Gracias, D. Zhang, L. Lianos, W. Ibach, Y. Shen, and G. Somorjai, "A study of the glass transition of polypropylene surfaces by sum-frequency vibrational spectroscopy and scanning force microscopy," Chemical Physics, vol. 245, no. 1-3, pp. 277284, 1999.

[8] T. Sterzyński, "Processing and property improvement in isotactic polypropylene by heterogeneous nucleation," Polimery, vol. 45, no. 11-12, pp. 786-791, 2000.

[9] C. Subramanian, S. B. Deshpande, and S. Senthilvelan, "Effect of reinforced fiber length on the damping performance of thermoplastic composites," Advanced Composite Materials, vol. 20, no. 4, pp. 319-335, 2011.

[10] C. Subramanian and S. Senthilvelan, "Effect of reinforced fiber length on the joint performance of thermoplastic leaf spring," Materials and Corrosion, vol. 31, no. 8, pp. 3733-3741, 2010.

[11] K. Panneerselvam, S. Aravindan, and A. Noorul Haq, "Study on resistance welding of glass fiber reinforced thermoplastic composites," Materials and Corrosion, vol. 41, pp. 453-459, 2012.

[12] P. Postawa, T. Stachowiak, and A. Szarek, "Badanie właściwości kompozytów drewno-polimer metodą DMTA (Dynamical mechanical research of properties of wood-polymer composite use DMTA method)," Kompozyty, vol. 10, no. 3, pp. 266-269, 2010.

[13] "Potters Industries LLC Engineered Glass Materials Division, High Performance Solid Glass Polymer Additives," http://www .velox.com/fileadmin/products/03-Additives/Potters/Brochures/ Potters_Solid_Spheres_Product_Charateristics.pdf, (Accessed: march 13, 2019).

[14] F. Rezaei, R. Yunus, and N. A. Ibrahim, "Effect of fiber length on thermomechanical properties of short carbon fiber reinforced polypropylene composites," Materials and Corrosion, vol. 30, no. 2, pp. 260-263, 2009.

[15] Y. X. Yang, R. Boom, B. Irion, D.-J. van Heerden, P. Kuiper, and H. de Wit, "Recycling of composite materials," Chemical Engineering and Processing: Process Intensification, vol. 51, pp. 53-68, 2012.

[16] "Materiały kompozytowe (Composite materials)," http://www .im.mif.pg.gda.pl/download/materialy_dydaktyczne/PIM_22_ materialy_kompozytowe.pdf, (Accessed: october 25, 2018).

[17] P. Palutkiewicz and P. Postawa, “The investigation of selected properties of the porous moulded parts from talc-filled PP composites," Journal of Cellular Plastics, vol. 52, no. 4, pp. 399418, 2016. 


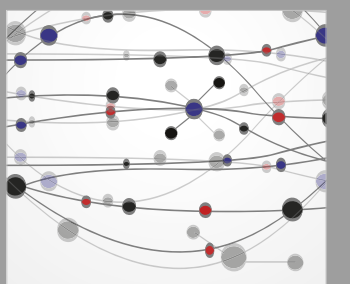

The Scientific World Journal
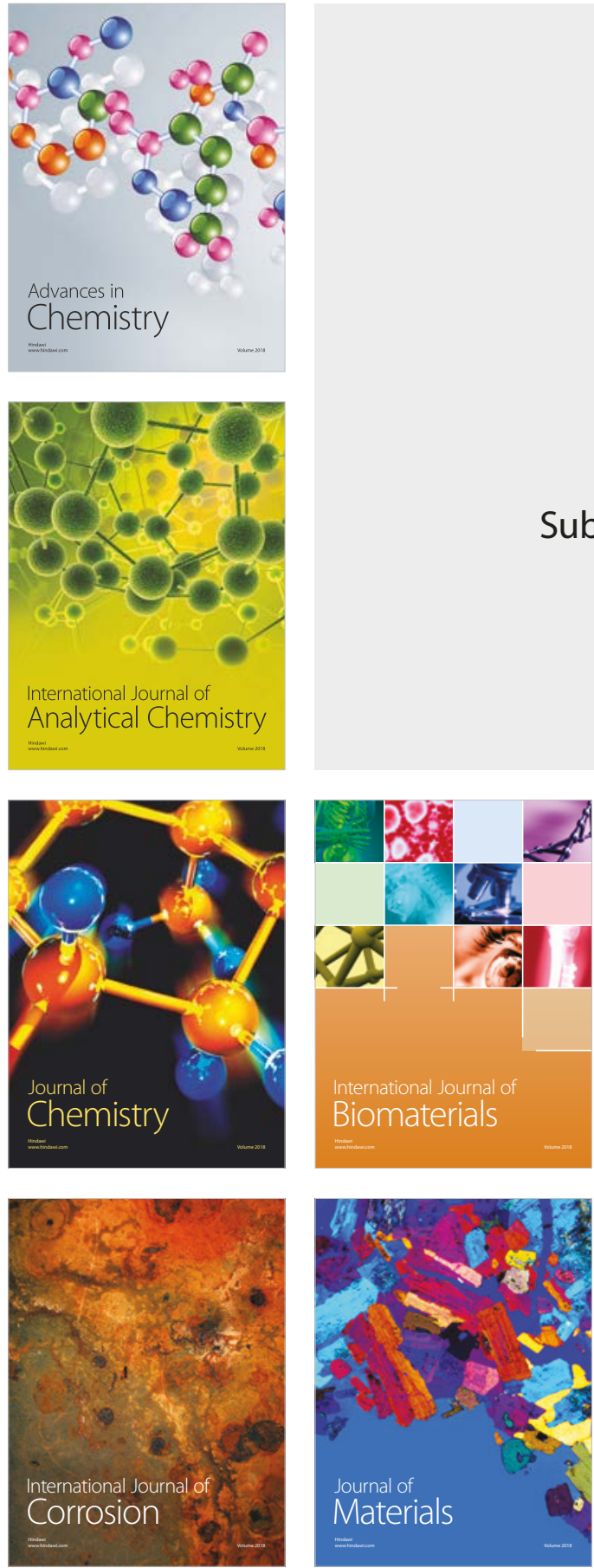

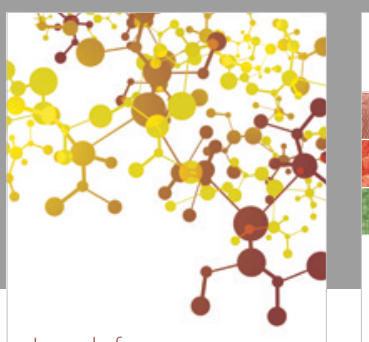

Journal of

Applied Chemistry
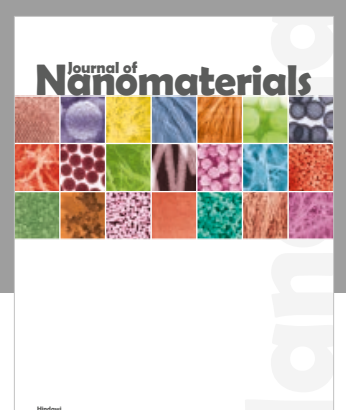

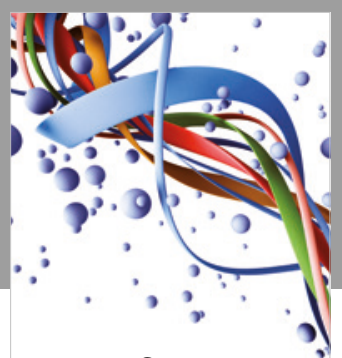

Scientifica

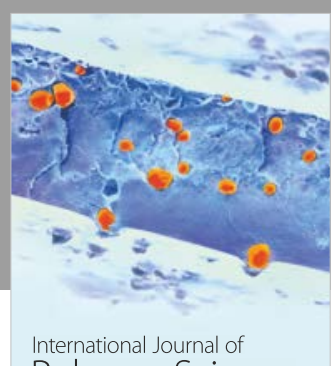

Polymer Science

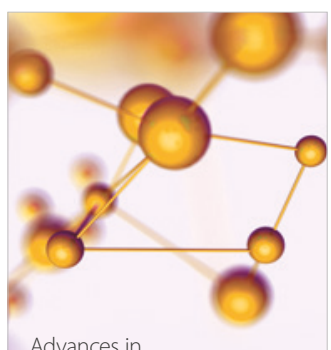

Physical Chemistry
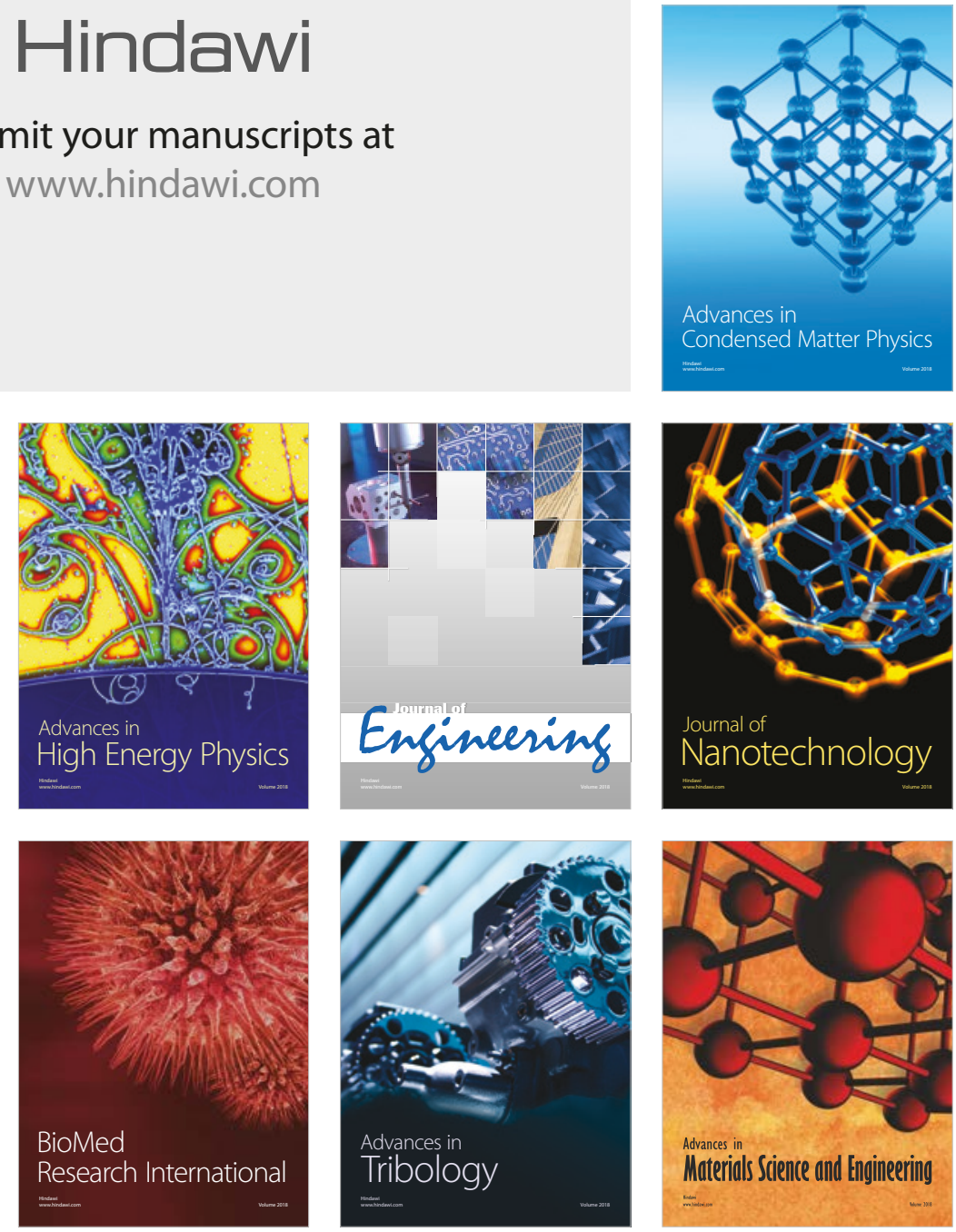